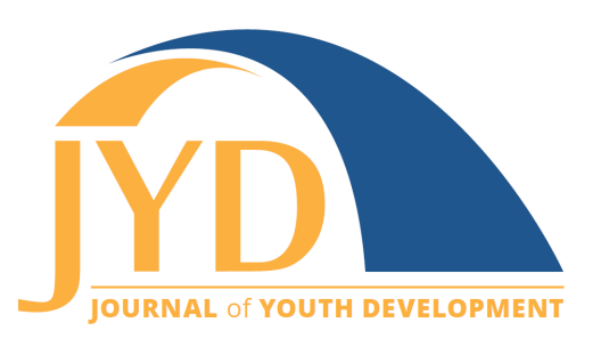

http://jyd.pitt.edu/ | Vol. 16 Issue 5 DOI 10.5195/jyd.2021.1106 | ISSN 2325-4017 (online)

\title{
Learning to Improve Program Systems While Navigating Program and Institutional Constraints
}

\author{
Erica Jeanne Van Steenis \\ University of California, Irvine \\ erica.vansteenis@uci.edu
}

\begin{abstract}
Many youth worker professional development (PD) efforts tend to focus on individualized skill development, rather than learning as a contextualized phenomenon that impacts youth workers' everyday experiences in the field. Youth worker learning is fundamentally embedded in a broader ecosystem of programs, institutions, and systems that influence how they make sense of and implement their learnings. Examining institutionalized experiences and how they shape youth workers' response to PD requires attention to the larger ecology of the contexts in which they work. In this paper, I analyze a PD initiative facilitated by a school district in the Rocky Mountain West. Data collected during the PD show that participating youth workers made changes to their program systems. At the same time, participants reported a range of institutional constraints that did not cohere with the PD. I bridge sensemaking theory to research on youth worker self-efficacy to unpack youth workers' reaction to and implementation of the $P D$, and I discuss implications for youth worker PD. I propose that PD efforts could more closely attend to youth workers' institutional contexts.
\end{abstract}

Key words: youth workers, professional development

Youth worker professional development (PD) initiatives offer opportunities for youth workers to develop knowledge that builds expertise, authority in the profession, and professional legitimacy (Baizerman \& VeLure Roholt, 2016; Quinn 2004). While useful for hiring processes, professional advancement, and a succinct articulation of the skills necessary to youth work (Starr et al., 2009), youth worker PD tends to focus narrowly on individualized skill development. Rather, youth worker learning is fundamentally shaped by context and embedded in a broader ecosystem of programs, institutions, and systems that influence how they make sense of and implement their learnings.

(cc) EY New articles in this journal are licensed under a Creative Commons Attribution 4.0 License. This journal is published by the University Library System, University of Pittsburgh and is cosponsored by the University of Pittsburgh Press. The Journal of Youth Development is the official peer-reviewed publication of the National Association of Extension 4-H Youth Development Professionals and the National AfterSchool Association. 
Researchers and practitioners alike could more intentionally examine youth workers' application of PD by taking stock of their learning as a part of and in relationship with the larger ecosystem. In particular, the ways in which youth workers make sense of PD interfaces with their programmatic and institutional experiences and can shape their sense of self-efficacy, or the agency they feel to take successful action within the ecosystem (Bandura, 1977; Tsang et al., 2012). PD that focuses narrowly on individual learning runs the risk of misalignment with program and institutional constraints youth workers face.

This study takes up an exploration of one youth worker PD in a large urban school district based in the Rocky Mountain West to explore the relationship between youth workers' individual learning and the contexts that influence their everyday experiences in the field (Walker \& Gran, 2010). I begin this paper by discussing the context in which the PD occurred including the mode of delivery, timeframe in which it occurred, and the subject matter that organized the sessions. Then, I bridge sensemaking (Weick, 1995) and self-efficacy (Bandura, 1977; Tsang, Hui, \& Law, 2012) theories to build a conceptual framework and subsequently present findings of youth workers' reaction to and implementation of the PD (Ross et al., 2011). Finally, I discuss the implications for youth worker PD more widely.

\section{Professional Development Context, Participants, and Features}

This study took place in a large urban school district, consisting of a network of 46 after-school programs managed by youth workers. In spring 2019, district administrators began a new initiative to create a multifaceted PD approach for youth workers across those 46 programs. To inform the topic, two of the district administrators named Ryan and Farshid, ${ }^{1}$ who also acted as focal participants in this study, conducted a needs assessment of 46 youth workers. The results of the needs assessment led Ryan and Farshid to design a curriculum focused on developing the youth workers' self-efficacy. The PD design focused on facilitating shifts in youth worker routines and practices at the individual and programmatic levels.

The PD targeted management level youth workers and drew on a district level framework called Youth Program Quality Assessment (YPQA) and from the New York Department of Youth \& Community Development's Core Competencies for Supervisors of Youth Work Professionals. ${ }^{2}$

\footnotetext{
${ }^{1}$ All names in this paper are pseudonyms.

2 Many of youth worker professional development efforts utilize the core competencies-frameworks that identify the characteristics that constitute youth work and subsequently the skills required of the job (Huebner et al., 2003). They inform training efforts like consultation, coaching, and training seminars; a wide variety of organizations have developed and leveraged core competencies in training their youth workers.
} 


\section{Improving Systems While Navigating Constraints}

Ryan and Farshid, intentionally keeping the PD small, identified four of the 46 youth workers to take the pilot PD—Daniel, Barrett, Elise, and Renee. Each of them had 3 to 5 years of experience working with youth but less experience in supervisory roles. The pilot consisted of eight sessions that took place for 2 hours each (16 hours total) at district offices. Each session took up an aspect of youth worker leadership, specifically inviting the youth workers to analyze their own practices and program structure to make incremental changes at their sites (see Table 1).

Table 1. Professional Development Session Topics

\begin{tabular}{|c|l|}
\hline $\begin{array}{c}\text { Week } \\
\text { Number }\end{array}$ & \\
\hline 1 & Introduction to the PD and Understanding Your Why \\
\hline 2 & Exploring Program Systems \\
\hline 3 & Building Program Systems Leadership Part I \\
\hline 4 & Building Program Systems Leadership Part II \\
\hline 5 & Developing Resourcefulness \\
\hline 6 & Flying by the Seat of Your Pants: Making Quick Decisions by Drawing on your Resources \\
\hline 7 & Systems Designs \\
\hline 8 & Final Redesign Presentations \\
\hline
\end{tabular}

Their curricular approach mediated the youth workers' reflective engagement on their practice. For example, the PD intended to provide support to the youth workers' self-assessment of routines and tools to identify and utilize resources that could contribute more fully to participant and program staff's growth (Figure 1). They workshopped how the staff and youth move through the space and aided the youth workers in developing a set of principles and procedures to positively maximize their programmatic structures. They also prioritized building a community amongst the youth workers in order to create a chance to share knowledge across each other. 
Figure 1. Self-Assessment Worksheet

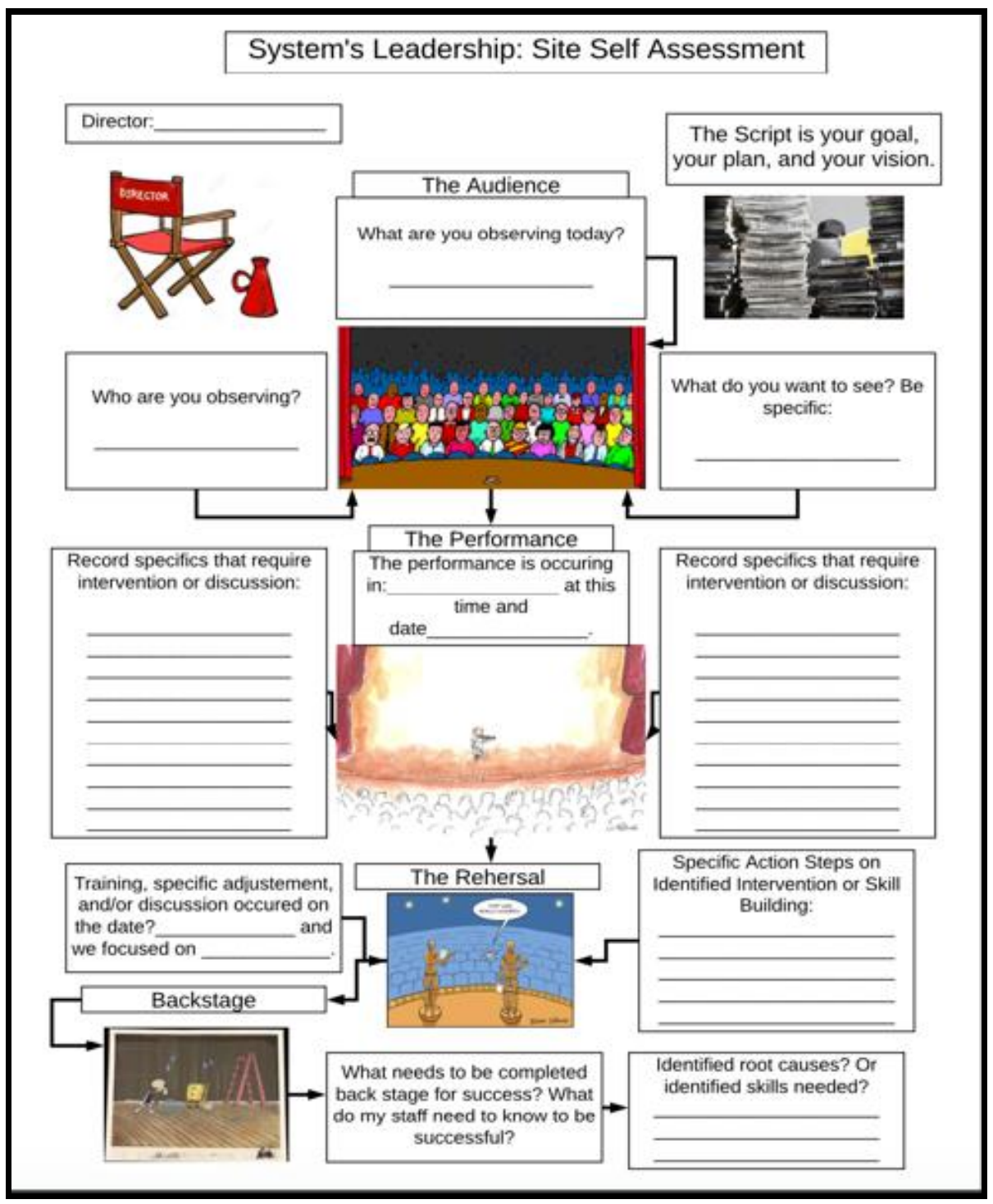

I partnered as a researcher with the district when Ryan and Farshid became interested in conducting a developmental evaluation of their initial PD efforts. As a researcher, I supported Ryan and Farshid's three relevant learning goals: Youth workers would learn to (a) effectively self-assess their practices, (b) identify and harness resources that allow for building routines that contribute to students' growth, and (c) develop tools to more fully support their staff. Building from these goals, Ryan and Farshid hypothesized that youth workers' program level routines and consequentially their self-efficacy would improve through participation in professional development. 


\section{Youth Worker Professional Development within a Broader Ecosystem}

\section{Positive Outcomes of Youth Worker Professional Development}

Extensive research on youth worker PD supports the district's vision that by offering quality PD initiatives they could retain adept leaders and more expansively support children and youth. For instance, research shows that youth worker PD has resulted in improvements in practice, reduction in staff turnover, and professionalization (Huang \& Cho, 2010; Zhang \& Byrd, 2005). Consequentially, program quality and outcomes for children and youth improve (Bowie \& Bronte-Tinkew, 2006; Huang \& Cho, 2010). Furthermore, a consistent thread in scholarship on youth worker PD is that by offering youth workers quality development opportunities, their sense of self-efficacy increases. Bowie and Bronte-Tinkew (2006), drawing on a study conducted by the Academy for Educational Development, followed up with youth workers after a PD series and found that "three-fourths of post-survey youth worker respondents indicated that training had a 'great deal' or 'good amount' of impact on their ability to handle the multiple roles ... and responsibilities expected of them" (p. 2). They found that a shared sense of selfefficacy retains youth workers in the profession at higher rates (see also: Baizerman \& VeLure Roholt, 2016; Bouffard \& Little, 2004; Dennehy et al., 2006; Huang \& Cho, 2010; Ross et al., 2011).

Another study commissioned by the U.S. Department of Education occurred in two parts and demonstrates how quality training improves youth workers' occupational investment. The National Afterschool Partnership (NAP) conducted the first part of the mixed-methods study with 53 programs of $21^{\text {st }}$ Century Community Learning Centers ( $21^{\text {st }}$ CCLCs) based on their annual performance reports or their profile information collection system. The NAP study indicated that the 53 programs had higher than national average staff retention with "43 percent of staff remaining at the same program for 3 to 5 years, 14 percent of the staff remaining at the same program for six to nine years, and nine percent of the staff remaining at the same program for 10 or more years" (Huang \& Cho, 2010, p. 10-11). The second part of the study, called the Extension Study, identified four of the 53 programs to further investigate and found that PD increased youth workers' sense of competence. PD efforts across the $21^{\text {st }}$ CCLCs bolstered youth workers' motivation, sense of belonging, and retention and showed that more than just periodical PD is necessary for program quality and staff retention (Huang \& Cho, 2010).

Research on quality youth worker PD illuminates that there is great potential for positive youth worker outcomes across spectrums. At the same time, research on youth worker PD tends to be decoupled from context, emphasizing instead individualized knowledge acquisition. The field, 
however, would benefit from more sufficient attention to how youth workers make sense of their learning across contextual arrangements, including programs, institutions, and the larger system (see Figure 2). This study takes place in a large urban school district comprised of individuals, a variety of programs and programmatic approaches, and the district as the centralized, organizing body. The setting in which this research takes place plays a particularly relevant role because youth work most often takes place as part of smaller community-based organizations that have may have no relationship to wider, organizing institutional entities.

\section{Figure 2. Conceptualizing Youth Worker Learning as Part of a Broader Ecology}

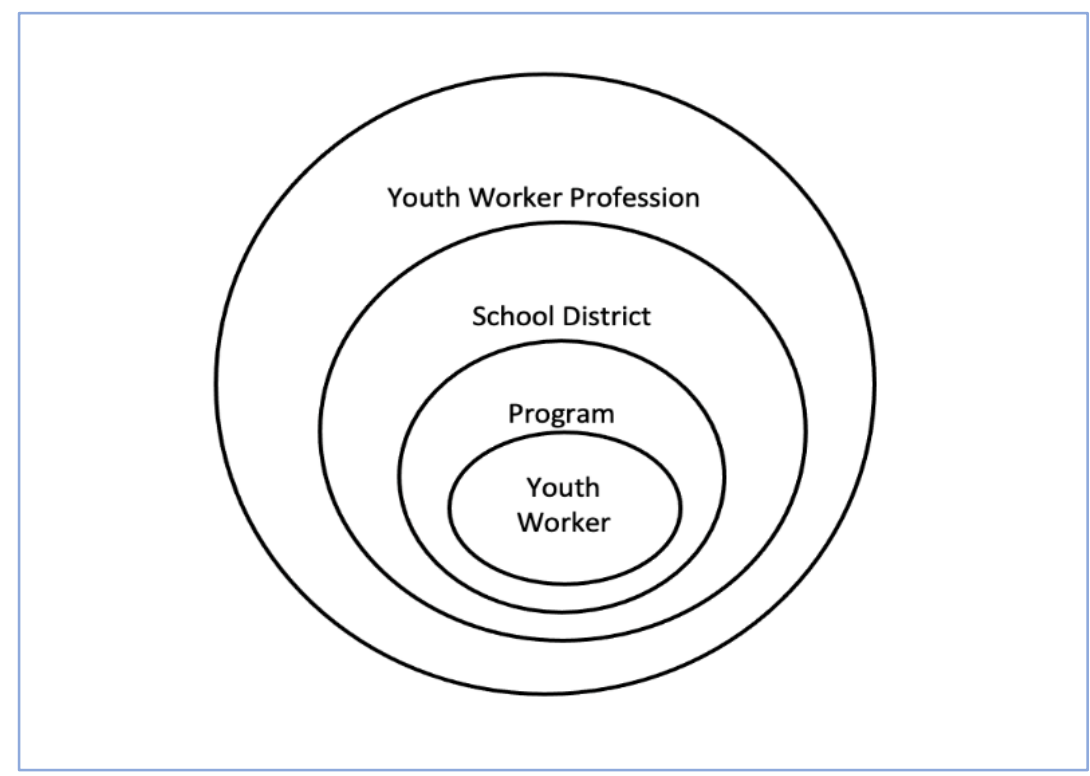

\section{Youth Workers Development of Self-Efficacy in Relation to Contextual} Arrangements

The relationship between youth workers and their broader contexts must be attended to in PD because it can have an impact on how youth workers develop self-efficacy. Self-efficacy, which tends to be a strong outcome focus of youth worker PD, contributes to individuals' sense of agency to think and to take successful action (Bandura, 1977). Indeed, youth workers' development of self-efficacy does not however occur in a vacuum but is shaped by how they make sense of their development in relation to contexts. From a sociocultural perspective, youth workers, at all stages of the profession, interface with culturally mediated tools and experiences across time and contexts and with the help of more experienced others (Vygotsky, 1978). Youth workers' experiences are entangled with, and sometimes frustrated by, intrusions from the broader contexts of their programs and districts. For instance, youth workers in this study consistently problem solved about misaligned district mandates, navigated 


\section{Improving Systems While Navigating Constraints}

miscommunications with district leaders, and dealt with various space allocation issues. As such, youth workers make sense of their work in terms of organizational affordances and constraints (see research on teacher sensemaking: Allen \& Penuel, 2015; Coburn, 2005) and tensions between individuals, programs, and institutions shape the enactment of learning (Weick, 1995).

This paper bridges studies of youth worker PD and self-efficacy to sensemaking theory (Weick, 1995) to analyze the experiences of four youth workers in the district facilitated PD. The findings raise important implications about the ways in which youth worker PD could more fully take stock of youth workers' broader contexts to account for the relationship between selfefficacy and the broader ecosystem of youth workers' practice.

\section{Research Methodology}

\section{Research Questions and Data Collection}

The following research questions framed this study:

1. What did youth workers learn by participating in the district PD?

2. What reflections did the youth workers share about their PD experience?

3. In what ways did youth workers make sense of the PD in terms of their programmatic, institutional, and systems-wide experiences?

To answer these questions, I bridged research on youth worker PD with research on youth worker self-efficacy and grounded it in practice by co-constructing it with Ryan and Farshid to meet their intended goals for the PD.

I collected multiple sources of data. First, Ryan and Farshid asked me to construct a survey protocol that could quantitatively capture the youth workers' perspectives before and after the PD. They intended to use the surveys to inform future iterations of the PD. The survey protocol included two parts. The first was informed by Harjte et al. (2008) and Ross et al.'s (2011) use of the Working with Youth Competency Scale. This scale included eight subscales with a total of 27 items based on Eccles \& Gootman's (2002) study of after-school programs and youth worker practice. The youth workers answered each question using a 10-point scale that ranged from "I am not good at this" to "I am extremely good at this." The second included Schwarzer and Jerusalem's (1995) General Self-Efficacy scale. This scale consists of 10 items with four response categories ranging from not true at al/ to exactly true. The survey included a qualitative section with self-reflective open-ended questions that asked the youth workers to reflect on their work and the PD. 


\section{Improving Systems While Navigating Constraints}

I also acted as participant observer and wrote field notes on the PD sessions, noting the activities, facilitator roles, and participation patterns (Spradley, 1979). These data supported an evaluatory approach that captured real-time feedback to support continuous development of future PDs (Patton, 2010). I debriefed with Farshid and Ryan each week, reflecting together on the curricular design of the PD and the participation patterns, and wrote memos following those meetings.

Third, to capture the youth workers' reflections on the PD, I designed an interview protocol with Ryan and Farshid and conducted interviews with each youth worker. Questions included the following categories: feedback about the PD series, application of site systems, on-the-job support, and self-efficacy. Finally, I used artifacts from the PD like reflective journal exercises, concept mapping, and spatial diagrams.

\section{Data Analysis}

The conceptual and practical purposes for conducting the PD-namely that the youth workers would deepen their sense of self-efficacy and improve routines and staff relations-guided my preliminary data analysis. I analyzed the data using interpretive qualitative methods, which foreground the meaning-making processes of participants-in-context (Erickson, 1986). This method of inquiry allowed me to focus on what youth workers described as important and worthy of consideration. I intended to capture youth workers' "local meanings" (Erickson, 1986, p. 119), and I paired this approach with descriptive quantitative analysis of the survey results. I attended to youth workers' self-assessments and personal resourcefulness, expressions of expertise and success. I examined the self-reported increase in competency scale results attending specifically to self-efficacy.

My initial analysis did not include a sensemaking lens, but patterns arose across the data indicating youth workers reflected on the relationship between their individual practice, programs, and institutional contexts. The sensemaking lens facilitated a focus on youth workers' reflections in so far as how they made sense of the affordances and constraints of the complex ecologies in which they worked. These codes included, for instance, reflections on their individual practice in relation to program and institutional constraints and sensemaking about those constraints in the context of the PD. 
Improving Systems While Navigating Constraints

Table 2. Excerpt From Codebook

\begin{tabular}{|c|c|c|c|}
\hline Parent code & Child code & Definition & Brief excerpt \\
\hline \multirow[t]{2}{*}{ Self-efficacy } & $\begin{array}{l}\text { Feelings that arise } \\
\text { including anxiety, } \\
\text { positivity, etc. }\end{array}$ & $\begin{array}{l}\text { When youth workers state } \\
\text { feelings about their practice. }\end{array}$ & $\begin{array}{l}\text { "I feel like I am doing an } \\
\text { effective job." }\end{array}$ \\
\hline & Expressions of growth & $\begin{array}{l}\text { When youth workers express } \\
\text { where they may grow their } \\
\text { practice to be more self- } \\
\text { efficacious. }\end{array}$ & $\begin{array}{l}\text { Alyssa explained that she } \\
\text { wants to develop even more } \\
\text { self-awareness because she } \\
\text { has noticed that the staff goes } \\
\text { "crazy" when she is not there. }\end{array}$ \\
\hline Sensemaking & Constraints & $\begin{array}{l}\text { When youth workers make } \\
\text { sense of constraints that } \\
\text { they face }\end{array}$ & $\begin{array}{l}\text { "Yeah, and then there's been } \\
\text { like ghost events that's what } \\
\text { I'm calling them. Where } \\
\text { they've set up for things and } \\
\text { I've confirmed with them that } \\
\text { there's no event, and then like } \\
\text { I have to convince the } \\
\text { custodians that there's no } \\
\text { event and they have to set up } \\
\text { like normal? So, I just call } \\
\text { those ghost events, so like no } \\
\text { we got the email." }\end{array}$ \\
\hline
\end{tabular}

\section{Findings}

The following findings advance two claims. First, supported by their being introduced to a repertoire of tools that expanded their sense of agency, the district PD led to robust changes to Daniel, Barrett, Elise, and Renee's programmatic routines. Second, even though the youth workers' sense of self-efficacy increased, programmatic and institutional constraints proved misaligned with the realities of their everyday experiences. 


\section{Improving Systems While Navigating Constraints}

\section{Development of Self-Efficacy Through the Implementation of New Routines}

A task of the PD asked Daniel, Barrett, Elise, and Renee to redesign an element of their programmatic structure that they thought needed improvement. In each case, their shifts to a program routine bettered participation from children, parents, and staff. Results from the preand post-PD surveys and interviews illuminated that such improvements increase the youth workers' sense of self-efficacy in their practice. Namely, Daniel, Barrett, Elise, and Renee developed a deeper capacity to facilitate strong programming and more fully support their front-line staff.

Daniel worked toward a simplified hourly schedule so that his staff and participants had more freedom to choose how they wanted to participate. Daniel's simplification of the hourly schedule and structure of his after-school program maximized the time that youth could engage actively outside. The simplification included that his staff worked with different groups of children and programs each day. He found that this structure gave youth more voice and choice in how they wanted to participate across the program. From his perspective, the restructured program led to staff feeling more useful and less frustrated with problematic participants. Daniel reported that the schedule changes helped to create more sustainable routines for staff, including interacting with different kids every day and gaining skills to work with different age groups. Consequently, Daniel also found that the routine change led to more happiness amongst parents and children. He told me, "Parents come up and say that their kids are super excited to be here . . . because they get to choose, together with their friends, which one they want to be with. And so that was a huge thing too." Furthermore, he found that the new program structure allowed the children to play with whomever they wanted to instead of others that the staff forced them to. Daniel felt especially happy in his decision to give children more play time and that his staff now knew more of the parents' names. He told me: "I do a great job, I think. I'm probably one of the best with the kids and with the parents."

Barrett focused on the social-emotional learning structure of his program by intentionally creating time for staff to check in with a number of children each day. This change included more attention to children's socio-emotional coping mechanisms. According to Barrett, his afterschool program included many students who could benefit from "control and management of their emotions in a healthier way than they are currently." He asked each staff member check in with five students at the beginning of the after-school program day. The daily check-in included more than just, "How are you doing today?"; staff asked "What do you need? What are you feeling?" and they asked children to "draw a picture of that emotion." In doing so, the staff worked with participants to move through their emotions into a more comfortable and aware 


\section{Improving Systems While Navigating Constraints}

space. Barrett witnessed positive outcomes from the staff's continued check-ins with five children each day, including that the staff came to him less, checked in more with parents more often, and dealt with behavioral issues directly.

Elise structured her program time so that her team had an increased ability to fulfill grant obligations for their program. She explained, "Yeah, I took homework out and I put in the grant program, and I made homework more of a choice activity versus this is something that kids have to do." Elise's move to provide more choice to the children regarding their homework required getting the parents "onboard" as well. A homework club provided the structure for children to choose whether or not they did their homework, but Elise and her staff no longer required it. Elise found that even though some parents expressed frustration, the extra time children had to play outside and participate in the grant-funded program led to positive outcomes. Like Daniel, the children experienced more freedom and therefore fewer behavioral issues occurred. This new routine also allowed Elise to work with her staff one-on-one to provide them with feedback on their performance; with fewer programs happening at once, Elise no longer had to be in the ratio of staff-to-children. I asked Elise if the routine changes allowed her to feel more confident in her work as a youth worker. She explained that she knew she did "something right because the kids loved her," and because she had worked for the district for 6 years. She told me: "I'm just really good with the kids . . . the kids are having fun; they're not messing around." Certainly, Elise's choice to provide her participants more freedom reflects her skill level with the children. She also reflected that her choices as a youth worker led to happier staff who planned to continue to work at the site even though her site is "known for having huge turnover and poor retention."

Renee used an organizational routine for identifying youth by using a card with each of their names. Renee changed her tracking card system that she felt caused a "bottleneck" and "hotspots" programmatically. The afterschool program Renee managed included over 200 children that participated across multiple different programmatic contexts on any given day. These included enrichment opportunities where children could explore their interests. Tracking cards represented each child in the program and allowed the site staff to keep track of where each child was throughout the day. Renee found that the tracking card system did not work for her because they would not have children pull their cards until after they went outside to play. This process meant that Renee did not have time to organize the children while they were outside, and she would spend an hour later in the day moving the children between playtime and their programs. Renee found that reorganizing the card-tracking system to have the children pull their cards as soon as they arrived led to significant positive outcomes. This 


\section{Improving Systems While Navigating Constraints}

change led to multiple positive outcomes. The programmatic flow led to smoother transitions where children moved outside quicker, allowing them to be in a playful environment, and the children experienced less frustration because they no longer had to line up to wait for more directions. When I asked Renee if she felt that she had improved as a youth worker, she said "immensely" because, like Elise, her staff seemed "less frustrated because we took out those hot spots in bottlenecks." Renee felt relief as the streamlined routine resulted in less frustration, stress, and anxiety across her staff and the participating children.

\section{Institutional Constraints as Barriers to Developing Organizational Efficacy}

Daniel, Barrett, Elise, and Renee experienced increased self-efficacy as a consequence of their successful actions of changing routines. At the same time, they faced institutional constraints organized across two dimensions. First, they lacked control over institution-wide changes, including staff retention, turnover, and licensing requirements. Second, they experienced mutual dependency on parts of the ecosystem in which they worked forcing them to act in concert with others and make challenging compromises. Sensemaking about their organizational contexts in the PD sessions acted as an undercurrent to the official task or topic and revealed the ways in which the PD appeared misaligned with the youth workers' realities.

\section{Staff Retention and Turnover}

The youth workers noted staff retention and turnover as a hurdle to their success. Many of their staff attended high school and college or had other commitments, like final exams, that caused them to leave before the school let out for summer. Elise explained that although her routine change resulted in success, "A struggle we recently had is staff turnover. I lost two staff members. So, we're in, like survival mode, you know 60 kids and three of us. You know so we're kind of just doing what we can." Daniel further highlighted the tensions that exist for youth workers when their staff leave earlier than anticipated. Referring to his staff Daniel stated, "I feel like they have a weird leverage over me because I don't want them to leave, because it's like if you, if they're good staff members you don't want them to go." Yet, he also recognized the challenges of being employed by the district: "it's a very part-time job, you know?" Daniel and Elise's experiences with staff show the potential strain of staff turnover especially as they lack the authority to increase retention.

Barrett described the issue further and a system for addressing the staff turnover issues, most especially the strain it puts on youth workers: 


\section{Improving Systems While Navigating Constraints}

I know our HR staff are continuously going through new resumes and they try to keep us updated on it but every time we go to hire someone it feels like it is a different process. I know there have been staff that have waited a month between getting hired and actually starting because of fingerprints. We have definitely lost a lot of people like oh I got a job ... I can't wait another 2 weeks.

Barrett believed that "only 1 in 5 will stay past a year or 2 but getting them past the 6-month or a year mark is really difficult." These issues with staffing reflected the district's capacity and ability to hire long term staff that they could pay and schedule in a sustainable way.

\section{District Licensing Requirements}

The ratio of staff to children challenged the youth workers as they worked to flexibly structure their programs. Renee described, from her perspective, the problematic nature of district licensing ratio requirements:

Like kids can't be unsupervised at any time. So, if I have a fifth grader who wants to walk down the hall and have a drink from the water fountain, I can't just say, yeah, cool, take a hall pass, which is what they do in day school. I have to physically have an adult with eyeballs on the child at all times, which is hard because then you've got somebody stepping out and you know how kindergartners are. One goes to the bathroom and then it's dominoes . . . it is a little frustrating sometimes.

This requirement results in staff being pulled from groups, forcing Renee, to rearrange her groups often. Renee explained that she wished she could give the children more independence to use the restroom by themselves or to travel across the space unsupervised. Renee described the impact of this reality on her practice, stating that she does not have the staff or bandwidth to always cover the requirements of licensing. Although she intended to always adhere to the policies and procedures, her ability to do so was directly linked to her energy, resources, and perceived abilities as a practitioner.

Renee faced further obstacles beyond her control regarding district licensing. Another layer of challenges she faced with district requirements related to her summer programming and IEP (individualized education plan) students with behavioral issues. She described to me that the district had filled her program to be overcapacity and that there were some kids who had behavioral needs. She explained:

So, we have this kid, he's extremely volatile. . . . He is registered into our program for next year. For the sake of equity and the district vision, 


\section{Improving Systems While Navigating Constraints}

collaboration, accountability, inclusiveness-all these things-we have to consider that he gets access. We can't deny him because he has an IEP."

The tension Renee described here is that district vision and licensing requirements directly contradict each other, putting her in a challenging position. She technically could not deny access to the child with the IEP, and she recognized the potentially discriminatory outcomes of that choice on the district's part. Nonetheless, sometimes district policies required Renee to take on the youth even if she did not feel safe doing so. An experienced practitioner, she struggled between regulations and professional and anticipated problems that could arise by taking this student into her program without adequate supervision. She also knew that following protocol was necessary in this instance because of issues of discrimination against students with IEPs.

\section{Space Allocation}

Across the data, Daniel brought up the issues experienced with the utilization of space in his program. His school had consistently allocated the basketball gym to other parties, and his space utilization became a pressing issue. Daniel, throughout the PD, often focused on his experience with displacement throughout his interview. He explained programmatically, even though he often planned to use the cafeteria or basketball court, he would have to compromise his plans because other parties utilized the spaces. Daniel felt that school leaders and schoolwide programmers paid inadequate attention to the needs of the after-school youth. Many people utilized the space including the community, and Daniel experienced a lack of communication about scheduling. When I asked him what this experience was like, he said the space allocation issues led to staff confusion: They "wouldn't know like when we're in the cafeteria. When we have all our space they know exactly where to go and what to do. And where to be and how to set-up how to break it down." He went on to explain that this directly affected staff and youth's behaviors:

Staff are like, "We're pent up in this cafeteria, we can't go outside, they can't run around. So, the kids are going crazy." . . . And then they're like, "Why am I doing this job?" And that leads to staff turnover. And then I end up, you have to do more hiring, the more you know? All of this stuff, it's just the trickle down is crazy. But if you can keep the kids happy, you have less behavior issues, that makes the staff happy. The staff think it's a good job, the staff want to stay. My job becomes a piece of cake, you know? Because then you're just, managing it and running it and teaching, then you have like the teaching opportunities where you're just like teaching how you want the program to be. 


\section{Improving Systems While Navigating Constraints}

This indicates that Daniel is unable to focus on the youth and fully do his job because he is managing the issue and taking care of his staff and youth who experience displacement.

The result of this for Daniel was a desire to leave the school and potentially the district. He perceived his job as harder than the other youth workers because of the space issues, noting that, "It's just like I said-it's just there's such a crazy disparity among the roles. . . . Who wouldn't want to be in a better situation with less stress and more space?" For Daniel, the stress of these issues began pushing him out of the district. He acknowledged his talent as a youth worker, but he believed that the institutional demands affected his ability to become a fully realized practitioner.

Barrett echoed Daniel's issue with space allocation, sharing that his principal hinders his growth as a youth worker because of the way she chooses to utilize his program space. He recounted: "She often uses the room we are going to use for meetings and things. It's sometimes this room ... sometimes it's the art room and she doesn't communicate that out very well. So, she will just show up and say these kids have got to go." To solve the issue, Barrett attempted to exercise some agency to get a master schedule that the school staff and administrators would use. He also shared that the after-school space had many other issues including that "hot water doesn't always flow . . . water fountains have really low water pressure so there are germs. The space and resources here are not great."

Indeed, youth workers' sense of self-efficacy mattered for changing program routines. In each case, the youth workers accomplished positive outcomes related to their personnel and programmatic management practices. The changes they made led them to reflect on the ways their sense of self-efficacy deepened. That said, the variety of institutional factors at the district level shaped how youth workers interpreted their ability to apply their PD learnings. They surfaced that institutional constraints disrupted and intruded on their programs, causing them to adjust and make compromises as needed.

The three institutional challenges discussed in this paper-staff turnover, licensing requirements, and space allocation-represent two types of constraints. One level of constraint is that these youth workers did not have control and authority over certain parts of the ecosystem in which they worked. For instance, they could not hire more staff or change staff hiring timelines and turnover. The youth workers also experienced constraints that related to a mutual dependency on others in the ecosystem, causing them to feel concerned with their staff, youth, and families. They could see the ways in which their perceived lack of authority had 


\section{Improving Systems While Navigating Constraints}

ripple effects on the program. The juxtaposition between positive outcomes for youth workers and institutional constraints raises important implications for practice.

\section{Recommendations for Practice}

Youth worker professional development maintains an intensive focus on individual learning and development of self-efficacy across various competencies. These findings, though a small group of participants, echo studies on positive impacts of youth worker PD on self-efficacy (Baizerman \& VeLure Roholt, 2016; Bowie \& Bronte-Tinkew, 2006; Yohalem et al., 2010). Relatedly, the findings also suggest that when youth workers produce change or look for better conditions, they are able to feel better about themselves in the job.

However, youth worker learning, and how they make sense of their learning in turn, is also shaped by broader systems and policies that present constraints. A question that the field could more fully consider is whether and how youth worker professional development efforts could better address youth workers' institutionalized realities. For instance, what would it have meant to the youth workers to have their institutionalized concerns included in the design of the professional development? The following points are recommendations provided in the spirit of more expansive PD designs and efforts to align training to youth workers' broader ecosystems.

- PD focused on site level systems proved successful for the youth workers, deepening their sense of self-efficacy. Youth workers who experience the agency to change systems and look for better conditions within their programs and succeed in effecting change can feel better about themselves in their job. A sense of efficacy across youth workers is useful for retention in the profession.

- Professional development efforts ought to include institutional level analysis and coaching on how to navigate institutional constraints. Relatedly, youth workers could learn the skills and knowledge to analyze systems of power present in the institutions in which they work. Training efforts could include problem solving exercises about district mandates that are misaligned with on-the-ground programming, miscommunications between institutional leaders and youth workers, and various space allocation issues. They could also build youth worker expertise for conversing across domains and stakeholders in the schools in which they work.

- Professional development efforts could be more grounded in youth workers' organizational experiences and how they make sense of them. Research that captures the voices of youth workers who participate in professional development efforts can provide feedback and insight that informs practice. 


\section{Improving Systems While Navigating Constraints}

- Even when youth workers do not surface institutional barriers, context always plays an important role in learning and development. Those who design and facilitate professional development would do well to consider how institutional contexts (mis)align and impact youth worker learning and development.

\section{Conclusion}

Youth work is represented by a broad group of practices that make it difficult to understand what constitutes the occupation and the qualities that should guide professional development. To date, youth workers have experienced a dearth of on-the-job professional learning and development opportunities (Huebner et al., 2003). Most PD opportunities occur as part of youth workers' on-the-job responsibilities and typically include site-specific orientations to introduce staff to organizational goals, short term training workshops, and performance management systems (Quinn, 2004). Furthermore, current PD efforts include a multitude of related frameworks created by institutions and practitioners to guide the structure for youth worker PD. These frameworks prove useful for hiring processes, professional advancement, and a succinct articulation of the skills and knowledge youth workers should possess (Starr et al., 2009).

While the field has provided an important starting point to youth worker PD, there is still insufficient guidance for youth worker learning, particularly as it relates to institutional constraints. Walker and Gran (2010) articulate this concern, arguing that, "By whittling down practice to the ability to undertake specific tasks, it becomes largely stripped of its social, moral, and intellectual qualities" (p. 2). For those who research and/or whose practice focuses on youth worker PD, the importance of PD design linked to context cannot be overstated. Like the PD efforts analyzed in this paper, supporting youth worker learning means more than a focus on self-efficacy. It also means folding in youth workers' attempts to cohere, or make sense of, what they learn as it relates to the ecosystem that shapes their on-the-ground realities.

\section{References}

Allen, C. D., \& Penuel, W. R. (2015). Studying teachers' sensemaking to investigate teachers' responses to professional development focused on new standards. Journal of Teacher Education, 66(2), 136-149.

Baizerman, M., \& VeLure Roholt, R. (2016). Youth worker professional development: Moving from practicing the symbolic to working substantively. In K. Pozzoboni \& B. Kirshner (Eds.), The changing landscape of youth work: Theory and practice for an evolving field (pp. 5171). Information Age. 
Journal of Youth Development | http://jyd.pitt.edu/ | Vol. 16 Issue 5 DOI 10.5195/jyd.2021.1106 Improving Systems While Navigating Constraints

Bandura, A. (1977). Self-efficacy: Toward a unifying theory of behavioral change. Psychological review, $84(2), 191$.

Bouffard, S. M., \& Little, P. M. (2004). Promoting quality through professional development: A framework for evaluation. Issues and Opportunities in Out-of-School Time Evaluation, 1(8). Harvard Family Research Project.

Bowie, L., \& Bronte-Tinkew, J. (2006). The importance of professional development for youth workers. Practitioner Insights Research to Results Child Trends, 2006(17), 13-24.

Coburn, C. E. (2005). Shaping teacher sensemaking: School leaders and the enactment of reading policy. Educational Policy, 19(3), 476-509.

Dennehy, J., Gannet, E., \& Robbins, R. (2006). Setting the stage for a youth development associate credential. National Institute on Out-of-School Time, Wellesley Centers for Women.

Eccles, J., \& Gootman, J. (Eds.). (2002). Community programs to promote youth development. National Academy Press.

Erickson, F. (1986). Qualitative methods in research on teaching. In M. C. Wittrock (Ed.) Handbook of research on teaching ( ${ }^{\text {rd }}$ ed., pp 119-161). Macmillan.

Hartje, J., Evans, W., Killian, E., \& Brown, R. (2008). Youth worker characteristics and self-reported competency as predictors of intent to continue working with youth. Child Youth Care Forum, 37, 27-41. (https://doi.org/10.1007/s10566-007-9048-9)

Huang, D., \& Cho, J. (2010). Using professional development to enhance staff retention. Afterschool Matters, 12, 9-16.

Huebner, A. J., Walker, J. A., \& McFarland, M. (2003). Staff development for the youth development professionals: A critical framework for understanding the work. Youth \& Society, 35(2), 204-225.

Patton, M. Q. (2010). Developmental evaluation: Applying complexity concepts to enhance innovation and use. Guilford Press.

Quinn, J. (2004). Professional development in the youth development field: Issues, trends, opportunities, and challenges. New directions for youth development, 2004(104), 13-24.

Ross, L., Buglione, S., \& Safford-Farquharson, J. (2011). Training the "wizards": A model for building selfefficacy and peer networks among urban youth workers. Child \& Youth Services, 32(3), 200-223.

Schwarzer, R., \& Jerusalem, M. (1995). Generalized Self-Efficacy Scale. In J. Weinman, S. Wright, \& M. Johnston (Eds.), Measures in health psychology: A user's portfolio. Causal and control beliefs (pp. 35-37). NFER-NELSON.

Spradley, J. P. (1979). The Ethnographic Interview. Wadsworth Cengage Learning.

Starr, B., Yohalem, N., \& Gannett, E. (2009). Youth work core competencies: A review of existing frameworks and purposes. Next Generation Youth Work Coalition. Retrieved February 22, 2020. (https://www.niost.org/pdf/Core_Competencies_Review_October_2009.pdf) 
Journal of Youth Development | http://jyd.pitt.edu/ | Vol. 16 Issue 5 DOI 10.5195/jyd.2021.1106 Improving Systems While Navigating Constraints

Tsang, S., Hui, E., \& Law, B. C. (2012). Self-efficacy as a positive youth development construct: A conceptual review. Scientific World Journal, 2012. (https://doi.org/10.1100/2012/452327)

Vygotsky, L. S. (1978). Mind in society: The development of higher psychological processes. Harvard University Press.

Walker, K., \& Gran, C. (2010). Beyond core competencies: Practitioner expertise as a critical component of quality. University of Minnesota Extension Center for Youth Development. (https://hdl.handle.net/11299/195259)

Weick, K. E. (1995). Sensemaking in organizations. SAGE.

Yohalem, N., Pittman, K., \& Edwards, S. (2010). Strengthening the youth development/after-school workforce: Lessons learned and implications for funders. The Forum for Youth Investment.

Zhang, J., \& Byrd, C. E. (2005). Enhancing the quality of after-school programs through effective program management. Journal of Physical Education, Recreation and Dance, 76(8), 5-10, 15. 